\title{
PREDICTIVE VALUE OF SERUM INTERLEUKIN 31 IN DIAGNOSIS OF OSTEOPOROSIS IN POSTMENOPAUSAL WOMAN: A NOVEL CASE-CONTROL STUDY FROM IRAQ
}

\author{
ASMA GHALIB ABID ${ }^{1}$, HAYFAA SALMAN AL-HADITHI ${ }^{2}$, FAIQ I GORIAL ${ }^{3}$ \\ ${ }^{1}$ Department of Infertility Treatment and IVF, Kamal Al-Samarai Hospital, Fertility Center, Baghdad, Iraq. ${ }^{2}$ Department of Microbiology, \\ College of Medicine, University of Baghdad, Baghdad, Iraq. ${ }^{3}$ Department of Medicine, College of Medicine, University of Baghdad, Baghdad, \\ Iraq. Email: faiqig@gmail.com \\ Received: 10 September 2018, Revised and Accepted: 16 October 2018
}

ABSTRACT

Objective: The objective of this study was to assess the predictive value of serum level of interleukin 31 (IL31) in diagnosis of osteoporosis (OP) in postmenopausal women.

Methods: This case-control study was conducted on 80 individuals, 50 of them with postmenopausal OP diagnosed using dual X-ray absorptiometry study, and the other 30 were healthy postmenopausal female controls. Serum level of IL31 was measured using enzyme-linked immunosorbent assay technique in both groups.

Results: The mean age of patients was $65.3 \pm 4.8$ years and controls was $61.1 \pm 3.9$ years. Mean serum IL31 level was significantly higher among postmenopausal patients with OP compared to healthy controls $(83.5 \pm 34.2 \mathrm{vs.} 34.9 \pm 7.3 \mathrm{ng} / \mathrm{ml}$, p<0.05). The optimum cutoff value of serum IL31 that can differentiate between patients with OP in postmenopausal women from controls was $>44.51 \mathrm{ng} / \mathrm{ml}$ with perfect positive predictive value (PPV) (100\%), very high accuracy of $92.5 \%, 88 \%$ sensitivity, $100 \%$ specificity, and negative predictive value (NPV) $83.3 \%$.

Conclusions: Serum IL31 level was significantly higher in postmenopausal osteoporotic women compared to healthy controls. It was a valid measure with high accuracy and perfect PPV and specificity, high sensitivity, and NPV. It can be used to confirm the diagnosis of OP in postmenopausal women.

Keywords: Serum interleukin 31, Postmenopausal women, Osteoporosis, Aging, Inflammation.

(C) 2018 The Authors. Published by Innovare Academic Sciences Pvt Ltd. This is an open access article under the CC BY license (http://creativecommons. org/licenses/by/4. 0/) DOI: http://dx.doi.org/10.22159/ajpcr.2018.v11i11.29647

\section{INTRODUCTION}

Osteoporosis (OP) is a disease characterized by low bone mass and microarchitectures destruction of bone tissue, leading to bone fragility and increased risk of fracture [1]. Postmenopausal OP is a common bone disorder in postmenopausal women and is caused primarily by estrogen deficiency resulting from menopause [2]. Due to its prevalence worldwide, $\mathrm{OP}$ is considered a serious public health concern [3]. In Iraq, the prevalence of OP in Iraqi postmenopausal women is $22.8 \%$ [4]. The underlying mechanism of OP is an imbalance between bone resorption and bone formation [5]. Interestingly, immune cells, mainly activated T-lymphocytes and antigen-presenting cells, can also express RANKL, therefore, influencing bone remodeling, both directly and through cytokine production [6]. For example, interleukin (IL)-6, IL-17, tumor necrosis factor- $\alpha$, and interferon- $\gamma$ promote bone loss by favoring osteoclast production and inhibiting osteoblast differentiation $[7,8]$. Other cytokines, such as IL-4, IL-12, and IL-33, are strong suppressors of osteoclast differentiation and inhibit bone loss $[9,10]$. In addition, many of these cytokines have pleiotropic functions and their role in bone remodeling is cell type and concentration dependent and also influenced by the variable cytokine network involved in different physiological and pathological conditions [11].

Local production of eicosanoids and IL is thought to participate in the regulation of bone turnover, and excess or reduced production of these mediators may underlie the development of OP [11]. This study was conducted to assess serum level of IL 31 in postmenopausal osteoporotic patient and healthy control and to determine optimal cutoff value for IL31 to differentiate between study groups.

\section{METHODS}

\section{Study design}

This case-control study was conducted at the Rheumatology Consultation Clinic of Baghdad Teaching Hospital/Medical City from
July 2016 to November 2016. Ethical permission to conduct the research was obtained from rheumatology unit/department of medicine and a signed consent was taken from each participant.

\section{Participants}

A total of 50 Iraqi postmenopausal female's patients with OP diagnosed by dual X-ray absorptiometry (DXA) spine and DXA hip which was diagnosed by rheumatologist according to the current criteria of the World Health Organization [12]. Females ages ranged from 55 to 76 years. Another 30 healthy volunteer female's subjects were taken as controls. They have no OP by DXA study and non-significant medical history.

\section{Data collection}

Full history was taken and complete clinical examination was done for all participants in the study. Data collected included age, weight, height, body mass index (BMI), smoking status, and the recent relevant investigations were recorded inform of C-reactive protein and erythrocyte sedimentation rate. None of the studied participants had pathologies causing secondary OP or took drugs that could affect bone metabolism.

\section{Measurements}

$4 \mathrm{ml}$ of venous blood sample was obtained from each subject and collected in a non-heparinized plain tube, then centrifuged at $1800 \times g$ for $10 \mathrm{~min}$ to separate serum. The obtained serum labeled and stored at $-20^{\circ} \mathrm{C}$ until use, no preservative was added. IL31 was detected by enzyme-linked immunosorbent assay technique at immunology department/teaching laboratories.

\section{Statistical analysis}

Statistical analysis was done using the Statistical Package for the Social Sciences version 20 IMB. Anderson-Darling normality test was used to test the distribution of variables by a Minitab version 17 software. Continuous variables were reported as mean \pm standard deviation 
when normally distributed. Categorical variables were presented as numbers and percentages. Difference between normally distributed continuous variables was done using independent $t$-test (Student's test). Difference between categorical variables was measured using Chi-square test. The optimum cutoff value of serum IL31 was calculated using receiver operating curve with its validity parameters (sensitivity, specificity, accuracy, positive predictive value [PPV], and negative predictive value). $\mathrm{p}<0.05$ was considered statistically significant.

\section{RESULTS}

The mean age of patients was $65.3 \pm 4.8$ years and for controls was $61.1 \pm 3.9$ years $(\mathrm{p}<0.001)$. Mean BMI for patients was $29.9 \pm 4.1 \mathrm{~kg} / \mathrm{m}^{2}$ and for controls was $28.9 \pm 2.7 \mathrm{~kg} / \mathrm{m}^{2}$ ( $\left.\mathrm{p}=0.180\right)$. Other baseline characteristics are shown in Table 1.

The mean serum IL31 was significantly higher in postmenopausal woman compared to healthy controls $(83.5 \pm 34.2$ vs. $34.9 \pm 7.3, \mathrm{p}<0.001)$ as shown in Fig. 1.

Serum IL31 was excellent test to differentiate between postmenopausal women with OP and healthy controls (area under the curve $[\mathrm{AUC}]=0.93$, 95 confidence interval $[\mathrm{CI}]=0.85-0.975, \mathrm{p}<0.001)$. Furthermore, at the optimum cutoff value $>44.51 \mathrm{ng} / \mathrm{L}$, s. IL31 showed highest accuracy of $92.5 \%$ with perfect PPV and specificity of $100 \%$ and high sensitivity of $88 \%$ and NPP of $83.3 \%$. This indicates that the test is excellent test to predict woman with postmenopausal OP and confirm the Dx with $100 \%$ as shown in Fig. 2 .

\section{DISCUSSION}

$\mathrm{OP}$ and associated fractures are an important cause of mortality and morbidity [13]. Early diagnosis and treatment can reduce postmenopausal fracture risk and its complications [14].

This study assessed the predictive value of s. IL31 in diagnosis of OP in postmenopausal woman. It showed that serum IL31 was excellent test to differentiate between postmenopausal women with OP and healthy controls with high accuracy and perfect PPV and specificity and high

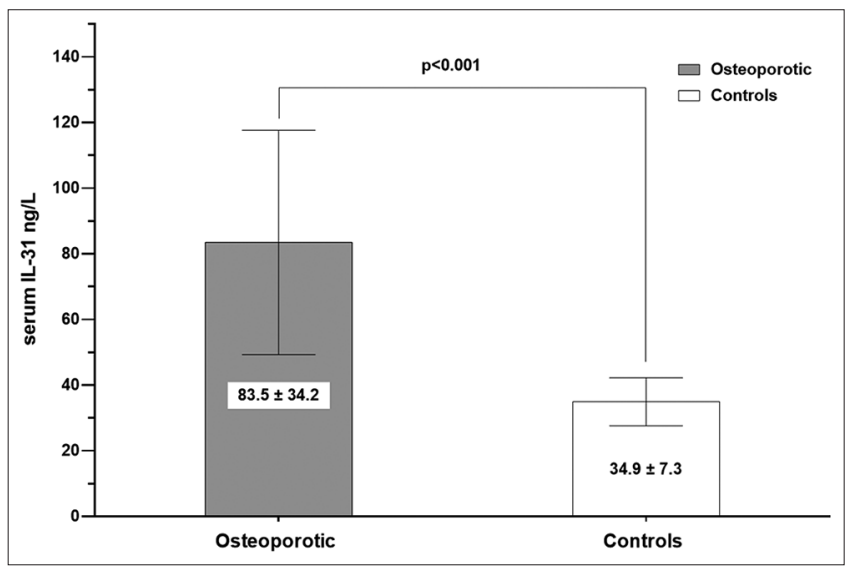

Fig. 1: Serum interleukin-31 in patients with osteoporosis and controls sensitivity and NPP. This is clinically important and may indicate that the test is excellent test to predict woman with postmenopausal OP and confirm the diagnosis with $100 \%$. The possible explanation of high serum IL-31 that we found in the postmenopausal osteoporotic patients might be related to the increased release of this cytokine by senescence inflammatory immune cells, and this could, therefore, contribute to the development of full-blown OP. The elevated IL-31 expression could enhance bone resorption through the induction of chemokines and pro-inflammatory osteoclastogenic cytokines, which subsequently lead to the recruitment of osteoclast precursors from the bone marrow, their differentiation, and activation [15].

The current study showed that the mean serum IL31 was significantly higher in postmenopausal woman with OP compared to healthy controls (83.5 \pm 34.2 vs. $34.9 \pm 7.3, \mathrm{p}<0.001)$. Moreover, serum IL31 was a valid test to differentiate between postmenopausal women with OP and healthy controls (AUC $=0.93,95 \mathrm{CI}=0.85-0.975, \mathrm{p}<0.001$ ). Furthermore, at the optimum cutoff value $>44.51 \mathrm{ng} / \mathrm{L}$, serum IL31 showed highest accuracy of $92.5 \%$ with perfect PPV and specificity of $100 \%$ and high sensitivity of $88 \%$ and NPP of $83.3 \%$. Similar finding reported by Ginaldi et al. [15] who demonstrated the increase of IL-31 serum levels in postmenopausal women with decreased bone mineral density. However, the current study reported for the $1^{\text {st }}$ time the predictive diagnostic validity parameters of serum IL31 in postmenopausal women with OP.

Several other studies showed that IL-31 stimulated secretion of proinflammatory osteoclastogenic cytokines, chemokines, and matrix metalloproteinases, all of which are implicated in differentiation, recruitment, and function of osteoclasts and are, therefore, key mediators of bone remodeling during aging [16-20].

The main limitation of this study is the small number of patients and controls and short duration of the study. Furthermore, we did not evaluate the severity of OP and whether serum IL31 correlates with it. This can be solved by a larger study size and longer duration. In spite of that, this study was the first study that evaluated validity of serum IL31 in diagnosis of OP in postmenopausal Iraqi women with strong inclusion and exclusion criteria.

\section{CONCLUSION}

Serum level of IL31 was significantly higher in patients with postmenopausal OP compared to healthy controls and was excellent valid test to predict $\mathrm{OP}$ in postmenopausal women with high accuracy and perfect PPV and specificity and high sensitivity and NPP. This suggests that serum IL31 might be used for early diagnosis and prevention of $\mathrm{OP}$ and subsequent better treatment.

\section{AUTHORS' CONTRIBUTIONS}

All authors were involved in drafting the article or revising it critically for important intellectual content, and all authors approved the final version to be published. Dr. Gorial had full access to all of the data in the study and takes responsibility for the integrity of the data and the accuracy of the data analysis.

\section{Study conception and design}

Asma Ghalib Abid, Hayfaa Salman Al-Hadithi, and Faiq I. Gorial. Acquisition of data: Asma Ghalib Abid. Analysis and interpretation of data: Faiq I. Gorial, Asma Ghalib Abid, and Hayfaa Salman Al-Hadithi.

Table 1: Clinical and anthropometric characteristics in the study group

\begin{tabular}{llll}
\hline Variables & Controls=30 & Osteoporotic $=\mathbf{5 0}$ & p value \\
\hline Age years, mean \pm SD & $61.1 \pm 3.9$ & $65.3 \pm 4.8$ & $<0.001$ (Significant) \\
BMI Kg/m ${ }^{2}$, mean \pm SD & $28.9 \pm 2.7$ & $29.9 \pm 4.1$ & 0.180 \\
Smoking status, $n(\%)$ & $6(20.0 \%)$ & $24(48.0 \%)$ & 0.012 (Significant) \\
ESR mm, mean \pm SD & $14.1 \pm 6.7$ & $21.6 \pm 8.0$ & $<0.001$ (Significant) \\
Positive CRP, $\mathrm{n}(\%)$ & $3(10 \%)$ & $14(28 \%)$ & 0.057 \\
\hline
\end{tabular}

SD: Standard deviation, n: Number, BMI: Body mass index, ESR: Erythrocyte sedimentation rate, CRP: C-reactive protein 


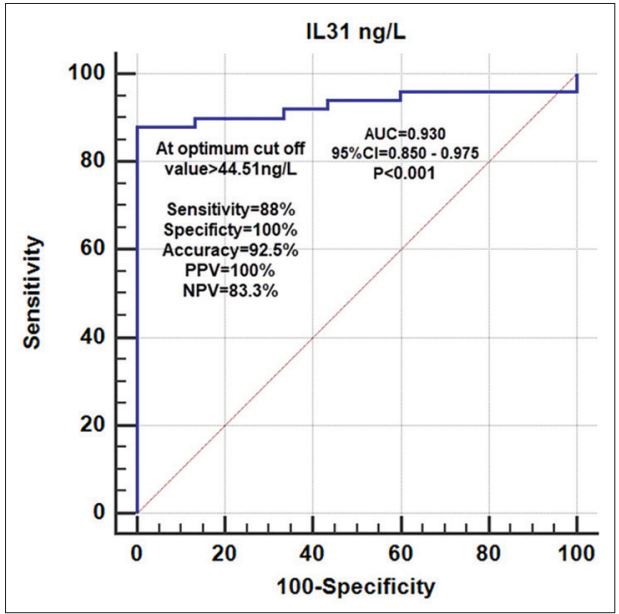

Fig. 2: Receiver operating characteristic test for serum interleukin 31 as a test to differentiate between postmenopausal women with osteoporosis and controls

\section{CONFLICTS OF INTEREST}

All the authors hereby declare that there are no conflicts of interest.

\section{REFERENCES}

1. Hendrijantini N, Alie R, Setiawati R, Astuti ER, Wardhana MP. Correlation of bone mineral density (BMD), body mass index (BMI) and osteocalcin in postmenopausal women. Biol Med (Aligarh) 2016;8. DOI: $10.4172 / 0974-8369$.

2. Feng X, McDonald JM. Disorders of bone remodeling. Annu Rev Pathol 2011;6:121-45.

3. Reginster JY, Burlet N. Osteoporosis: A still increasing prevalence. Bone 2006;38:S4-9.

4. Gorial FI, Abuaese ND, Hnasaeen NH. Prevalence and associated factors of osteoporosis in post-menopausal Iraqi women: A cross sectional two centers study. Int J Mod Biol Med 2013;3:41-9.

5. Wu S, Liu Y, Zhang L, Han Y, Lin Y, Deng HW, et al. Genomewide approaches for identifying genetic risk factors for osteoporosis. Genome Med 2013;5:44.
6. Weitzmann MN, Pacifici R. T cells: Unexpected players in the bone loss induced by estrogen deficiency and in basal bone homeostasis. Ann N Y Acad Sci 2007;1116:360-75.

7. McLean RR. Proinflammatory cytokines and osteoporosis. Curr Osteoporos Rep 2009;7:134-9.

8. David JP, Schett G. TNF and bone. Curr Dir Autoimmun 2010;11:135-44.

9. Fujii T, Kitaura H, Kimura K, Hakami ZW, Takano-Yamamoto T. IL-4 inhibits TNF- $\alpha$-mediated osteoclast formation by inhibition of RANKL expression in TNF- $\alpha$-activated stromal cells and direct inhibition of TNF- $\alpha$-activated osteoclast precursors via a T-cell-independent mechanism in vivo. Bone 2012;51:771-80.

10. Saleh H, Eeles D, Hodge JM, Nicholson GC, Gu R, Pompolo S, et al. Interleukin-33, a target of parathyroid hormone and oncostatin m, increases osteoblastic matrix mineral deposition and inhibits osteoclast formation in vitro. Endocrinology 2011;152:1911-22.

11. Zupan J, Jeras M, Marc J. Osteoimmunology and the influence of pro-inflammatory cytokines on osteoclasts. Biochem Med (Zagreb) 2013;23:43-63.

12. WHO Scientific Group on the Assessment of Osteoporosis at Primary Health Care Level, Summary Meeting Report. Geneva, Switzerland: World Health Organization; 2004. Available from: http://www.who.int/ chp/topics/Osteoporosis.pdf.

13. Kumar AV, Joseph AK, Gokul G, Alex MP, Naveena G. Clinical outcome of calcium, Vitamin D3 and physiotherapy in osteoporotic population in the Nilgiris district. Int J Pharm Pharm Sci 2016;8:157-60.

14. MiraÇi M, Demeti A, Ylli Z, KelliÇi S, Tarifa D. The cost-effectiveness of ibandronate and alendronate for the treatment of osteoporosis in a specialized clinic in Tirana. Int J Pharm Pharm Sci 2015;7:207-11

15. Ginaldi L, De Martinis M, Ciccarelli F, Saitta S, Imbesi S, Mannucci C, et al. Increased levels of interleukin 31 (IL-31) in osteoporosis. BMC Immunol 2015;16:60.

16. Zhang Q, Putheti P, Zhou Q, Liu Q, Gao W. Structures and biological functions of IL-31 and IL-31 receptors. Cytokine Growth Factor Rev 2008; 19:347-56.

17. Castellani ML, Felaco P, Galzio RJ, Tripodi D, Toniato E, De Lutiis MA, et $a$. IL-31 a cytokine involved in immunity and inflammation. Int J Immunopathol Pharm 2010;23:709-13.

18. Kasraie S, Niebuhr M, Werfel T. Interleukin (IL)-31 induces proinflammatory cytokines in human monocytes and macrophages following stimulation with staphylococcal exotoxins. Allergy 2010;65:712-21.

19. Cornelissen C, Lüscher-Firzlaff J, Baron JM, Lüscher B. Signaling by IL-31 and functional consequences. Eur J Cell Biol 2012;91:552-66.

20. Lencel P, Magne D. Inflammaging: The driving force in osteoporosis? Med Hypotheses 2011;76:317-21. 